\title{
Prediction of Yoshida Uemori model parameters by the bees algorithm and Genetic Algorithm for 5xxx series aluminium alloys
}

\section{$5 \times x \times$ serisi alüminyum alaşımları için Yoshida Uemori model parametrelerinin arı algoritması ve genetik algoritma ile tahmini}

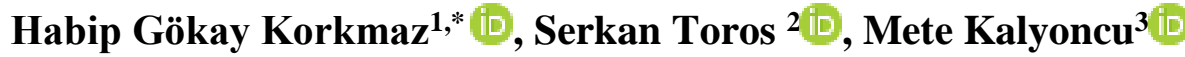 \\ 1,2 Department of Mechanical Engineering, Nigde Omer Halisdemir University, Nigde, Turkey \\ 1,3 Department of Mechanical Engineering Konya Technical University, Konya, Turkey
}

\begin{abstract}
In sheet metal forming processes, springback is a very important issue in the view of the excellent quality design. Several mathematical models have been developed to estimate the springback more accurately, including various material parameters. In this study, the model parameters of Yoshida-Uemori two surface plasticity model, which can well predict the springback for different loading conditions, have been determined using The Bees Algorithm and Genetic Algorithm which are frequently used recently for optimization of nonlinear problems. In addition, the performances of the algorithms have been determined for the different frequency of experimental data, dense-sparse, sparse-dense, dense-dense and sparse-sparse for elastic and plastic regions. According to the results, although the determined material parameters have different values, the fitting performances are found similar for both The Bees Algorithm and Genetic Algorithm. However, in the view of the data frequency, the more appropriate results are obtained from the dense-dense data set (Case 3).
\end{abstract}

Keywords: Yoshida Uemori model parameters, Optimization, The Bees Algorithm, Genetic Algorithm

\section{Introduction}

In metal forming processes, springback is an important problem that needed to be overcome. There are many modelling studies in the literature to determine the springback characterization of the sheet materials [1-4]. The models used for the springback prediction include complex mathematical operations including the anisotropic behaviour of the materials and the hardening models. When the sheet metals are stamped, they may exhibit different properties in compression and drawing directions. This is called as the Bauschinger effect [5] which is explained by the dislocation theory. It has been observed that the methods involving different deformation combinations, such as cyclic tensile and compression, used for the determination of mathematical models, have increased their ability to predict springback [6, 7]. One of the models that best simulates the Bauschinger effect is the isotropic-kinematic hardening model combined with two surface plasticity models. The most commonly used
Özet

Sac metal şekillendirme işlemlerinde tasarım kalitesinin mükemmelliği açısından geri esneme çok önemli bir yer teşkil etmektedir. Geri esnemelerin tahmini için birçok matematiksel model geliştirilmiş olup bu matematiksel model parametrelerinin belirlenmesi için birçok yöntem kullanılmaktadır. Bu çalışmada farklı yükleme koşulları için geri esnemeyi çok iyi tahmin edebilen Yoshida-Uemori iki yüzeyli plastisite malzeme model parametreleri, son zamanlarda doğrusal olmayan problemlerin optimizasyonu için sıkça kullanılan "Arı Algoritması" ve "Genetik Algoritma" kullanılarak belirlenmiştir. Aynı zamanda deneysel veriler elastik ve plastik bölgede sirasıyla; sıkseyrek, seyrek-s1k, s1k-sık ve seyrek-seyrek olacak şekilde ayarlanarak veri yoğunluğunun parametre sonuçlarına etkisinin incelenmiştir. Elde edilen sonuçlara göre belirlenen malzeme parametreleri farklı değerlere sahip olmasına rağmen Arı Algoritması ve Genetik Algoritma için uyum performansı yaklaşık olarak benzer çıkmıştır. Ancak sonuçlar data sıklığı açısından incelendiğinde sık-sık (Durum 3) veri kümesi daha iyi sonuçlar vermiştir.

Anahtar kelimeler: Yoshida Uemori model parametreleri, Optimizasyon, Ar1 Algoritmas1, Genetik Algoritma

two surface plasticity model is Yoshida Uemori [8]. This model can work with any anisotropic yield criterion, as well as to define the modulus of elasticity as variable with the given deformation.

Although the Yoshida-Uemori model predicts springback with high accuracy due to the complex mathematical operations associated with each other, it is difficult to find the model parameters due to these complex expressions, and special test tools are required to perform tensile and compression tests. There are various experimental and numerical methods in the literature to obtain cyclic loading behaviour. One of the most commonly used cyclic tests is the cyclic tensile test where sheets of special geometry are nipped between lubricated sheets to prevent buckling [9-12]. Different applications have been made for the determination of complex mathematical model parameters which are difficult to solve. For example; Chang et al. [13] using the regression method with a series of procedures they followed, they determined the Yoshida-

\footnotetext{
* Sorumlu yazar / Corresponding author, e-posta / e-mail: hkorkmaz@ohu.edu.tr (H. G. Korkmaz)

Geliş / Recieved: 07.03.2021 Kabul / Accepted: 05.05.2021 Yayımlanma/Published: 27.07.2021

doi: 10.28948/ngumuh. 895920
} 
Uemori model parameters. Using LS-Dyna finite element analysis program, MAT-125 material card, they used simulations for cyclic and shear tests to verify their model parameters. The data obtained from the analysis indicated that they simulated experimental curves correctly.

Since Yoshida Uemori model and similar models, it is difficult to determine the material model parameters, some authors have tried to determine the material parameters by using optimization method. For example, in two different studies, Eggertsen at al. [14, 15] determined both YoshidaUemori parameters using LS-OPT, the optimization tool of the LS-Dyna analysis program, by performing both bending and tensile-compression tests. The authors stated that the results obtained by this method in one of their studies gave much better results than the classical method, and in the other study, the data obtained from both types of experiments were equal in terms of accuracy. However, due to buckling problems experienced in tensile-compression tests, they stated that the bending test was an easier method. Toros [16] obtained the Yoshida Uemori model parameters using LSOPT, the optimization tool of the LS Dyna analysis program. He determined that this new approach yields better results than those obtained only by cyclic experiments and stated that the results of the numerical analysis and experimental results were very close. Chaboche, a kinematic stiffening model like Mahmoudi at al. [17] Yoshida Uemori, used a multipurpose Genetic Algorithm to determine the material model parameters. They stated that limit values are extremely important when using Genetic Algorithm and model parameters obtained by optimization give better results than those obtained by classical techniques. Li at al. [18] Yoshida Uemori and the homogeneous yield functionbased anisotropic hardening (HAH) material models with high springback prediction capability have determined the model parameters by using global optimization approach. They made U-shaped bending analyses with the obtained model parameters and compared them with experimental data. They stated that both material models were similar to experimental results.

In this study, cyclic tensile-compression experimental data will be used to determine Yoshida Uemori model parameters with the help of The Bees Algorithm and Genetic Algorithm, which is one of the optimization techniques that have recently optimized the solution of nonlinear problems. Although there are similar studies in the literature with the Genetic Algorithm, no study has been found about the finding of material parameters with The Bees Algorithm.

\section{The Bees Algorithm and Genetic Algorithm}

\subsection{The Bees Algorithm}

The Bees Algorithm is an optimization solution tool that mimics the food finding behaviour of honey bees in nature. Many works [19-28] explains in detail The Bees Algorithm. The Bees Algorithm requires a number of parameters to be set as explained in Table 1. The flowchart of The Bees Algorithm for constrained optimization problems is as shown in Figure 1. In its simplest form, The Bees Algorithm works as follows; The $\mathrm{n}$ bee is randomly distributed to the search space. The suitability of the sites visited by these bees is evaluated. The highest fitnesses $m$ sites are chosen for neighbourhood search. The neighbourhood search is conducted in the selected sites and assigned more bees to the best $\mathrm{e}$ sites. The probability of sites being selected is determined according to them fitness values. Searches in the neighbourhood of the best e sites are made more detailed by recruiting more bees. Only the one bee with the highest fitness will be selected to the next bee population. The remaining bees in the population are randomly assigned to space again within the specified constraint conditions for new potential solutions. The iterations are repeated until a stopping criterion is fitted.

Table 1. Required parameters used in The Bees Algorithm

\begin{tabular}{cl}
\hline Notation & Explanation \\
\hline $\mathrm{n}$ & Number of scout bees \\
$\mathrm{e}$ & Number of elite selected sites \\
$\mathrm{m}$ & Number of best selected sites \\
$\mathrm{nep}$ & Number of recruited bees around elite selected sites \\
$\mathrm{nsp}$ & Number of recruited bees around best selected sites \\
$\mathrm{ngh}$ & Patch radius for neighbourhood search \\
itr & Iteration number (Stop criterion) \\
\hline
\end{tabular}

\subsection{Genetic Algorithm}

Genetic algorithm (GA) is one of the commonly used optimization techniques that mimic natural selection and genetics. GA scans search areas that contain possible solutions and generates populations from individual points in these search areas many times. Each new generation improves population solutions become better.

In this study, Genetic Algorithm Solver in the Optimization Toolbox [29] in MATLAB software, which is a capable and useful tool, was used to solve optimization problems.

In its simplest form, the Genetic Algorithm includes the following steps;

- Coding of Solutions

- Creating the First Population

- Calculation of Compliance Value

- Application of Replication Process

- Implementation of Cross Transactions

- Application of Mutation Process

- Formation of a New Generation and Stopping the Cycle.

To determine the prediction performance of the models for each iteration, a fitness function which is given in Equation (1) is described. As can be seen from the equation, the minimization process is established on the differences of the calculated and experimental stress values for each point.

$$
\operatorname{Err}=\operatorname{Min} \frac{1}{K} \sum_{i=1}^{K}\left[\frac{\left(\sigma_{i}^{\text {exp }}-\sigma_{i}^{\text {model }}\right.}{\sigma_{i}^{\text {exp }}}\right]^{2}
$$




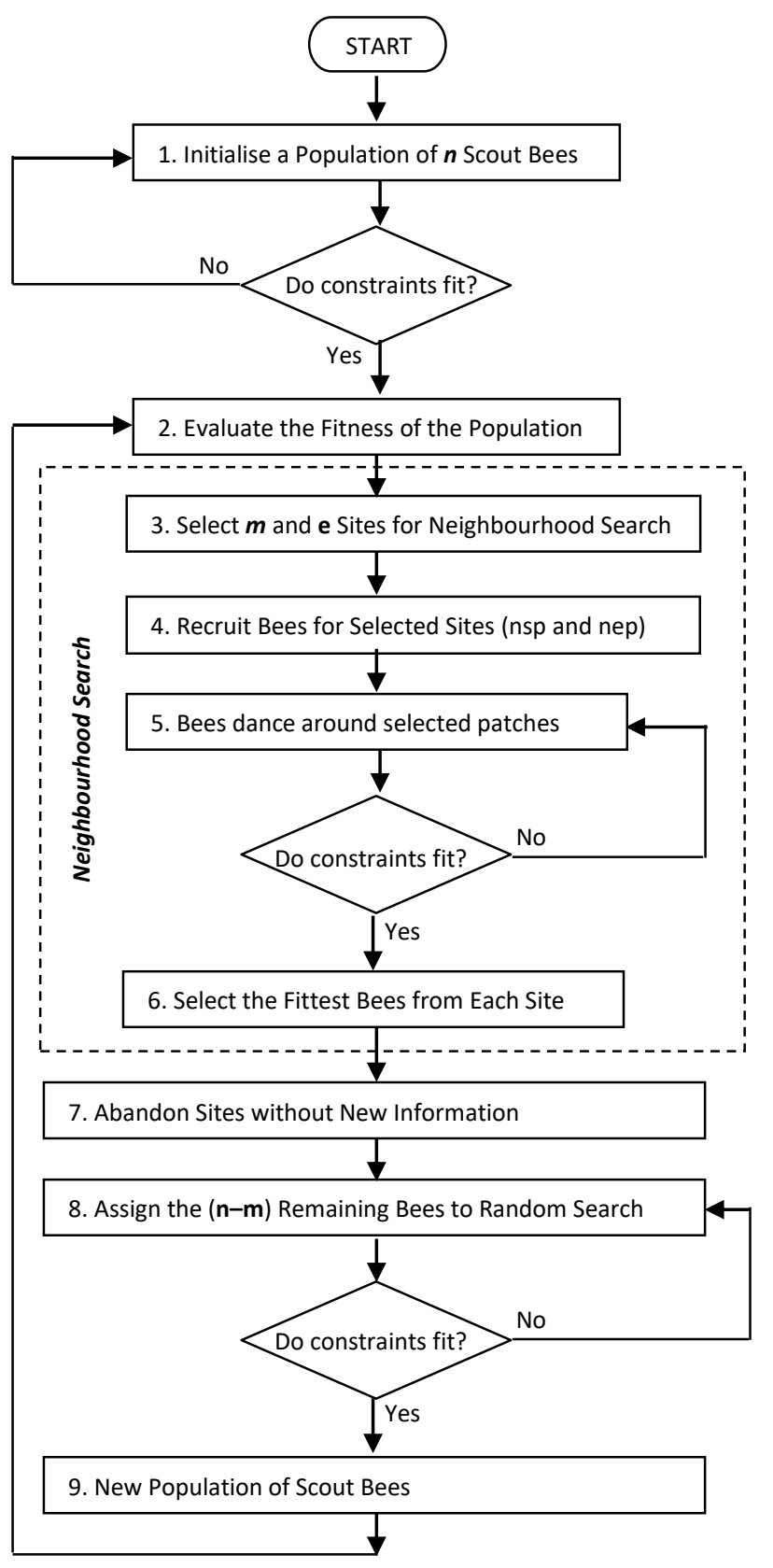

Figure 1. Pseudo code of The Bees Algorithm for constrained optimization problems

\section{Isotropic, kinematic hardening rule of Yoshida Uemori}

The Yoshida-Uemori two surface plasticity model is established for modelling of the kinematic behaviour of the yield surface within a bounding surface. The prediction capability of the model for the Bauschinger effect and the work hardening stagnation with the given reverse deformations, is the main powerful side. Since it can predict the cyclic stress-strain relation of the materials in a higher accuracy, the model is used in many commercially available finite element simulation software like Ls-Dyna and PamStamp. The high accuracy on the prediction of the springback of materials was proven by many researchers [30, 31]. The two moving yield contour and their kinematic motions are given in Figure 2.

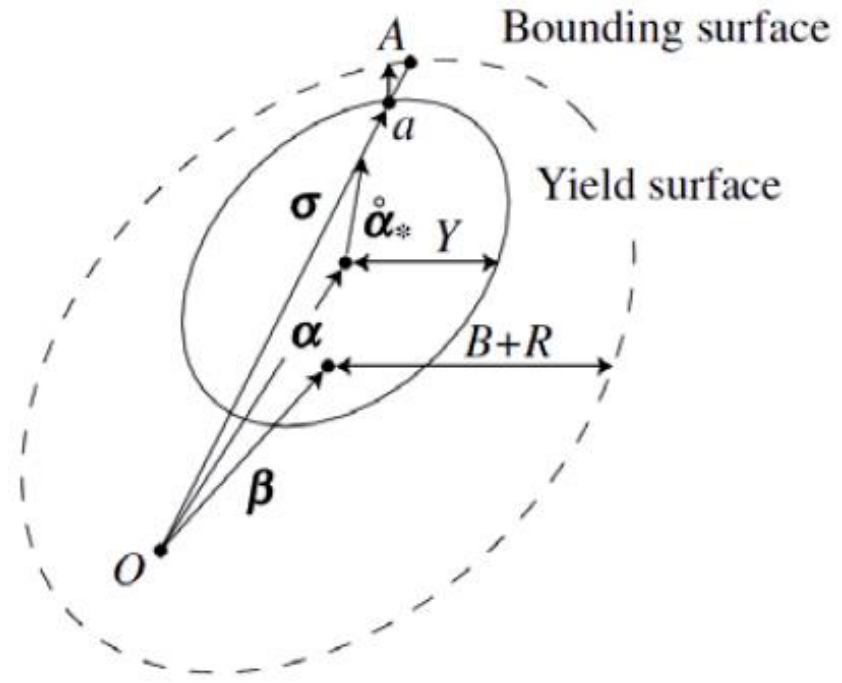

Figure 2. Schematic explanation of the two moving surface Yoshida-Uemori model

In the model, the yield contour's mathematical function can be defined as follow:

$$
f_{0}=\varphi(\boldsymbol{\sigma})-Y=0
$$

Since the model can be used with the anisotropic yield functions, $\varphi(\sigma)$ can be specified as an anisotropic yield criterion where the $\sigma$ is the Cauchy stress tensor and $Y$ is the initial yield strength of the materials. In the studied Y-U hardening model, as an anisotropic yield criterion the quadratic Hill-48 is chosen. The materials may have early yielding since the dislocation movement can be provided with less shear forces during the reverse loading conditions. Therefore, the yield contour is assumed to be kinematic hardening while the bounding surface is combined hardening behaviour. The kinematic motion of the yield contour can be defined as:

$$
f_{0}=\varphi(\boldsymbol{\sigma}-\boldsymbol{\alpha})-Y=0
$$

In the given equation, $\boldsymbol{\alpha}$ is the back-stress which varies with the applied effective plastic strain rate and the bounding surface $\mathrm{F}$ can be expressed with an additional parameter that shows the center of the bounding surface $\boldsymbol{\beta}$ as:

$$
F=\varphi(\boldsymbol{\sigma}-\boldsymbol{\beta})-(B+R)=0
$$

Where the $B$ and $R$ are the initial size and isotropic hardening component of the bounding surface and $B+R$ represents the size of the bounding surface. The kinematic motion of the yield contour with respect to the bounding surface is expressed as:

$$
\boldsymbol{\alpha}_{*}=\boldsymbol{\alpha}-\boldsymbol{\beta}
$$

Where the $\boldsymbol{\alpha}$ and $\boldsymbol{\beta}$ can be defined for different orientations: 


$$
\begin{gathered}
\boldsymbol{\alpha}=\left(\begin{array}{l}
\alpha_{11} \\
\alpha_{22} \\
\alpha_{12}
\end{array}\right) ; \boldsymbol{\beta}=\left(\begin{array}{l}
\beta_{11} \\
\beta_{22} \\
\beta_{12}
\end{array}\right) \\
\dot{\alpha}_{*}=C\left[\left(\frac{\alpha}{Y}\right)(\boldsymbol{\sigma}-\boldsymbol{\alpha})-\sqrt{\frac{\alpha}{\overline{\boldsymbol{\alpha}}_{*}}} \boldsymbol{\alpha}_{*}\right] \dot{\bar{\varepsilon}}
\end{gathered}
$$

Where $\overline{\boldsymbol{\alpha}}_{*}$ is the equivalent form of the kinematic motion of the yield surface with respect to the bounding surface $\left(\overline{\boldsymbol{\alpha}}_{*}=\varphi\left(\boldsymbol{\alpha}_{*}\right)\right)$ while $\alpha$ can be found via the following equation:

$$
a=B+R-Y
$$

In above equation, $\mathrm{Y}$ is the size of the yield surface and is constant throughout the deformation process.

The provisional prediction in size and center of the bounding surface can be expressed as:

$$
\begin{gathered}
\dot{R}=k\left(R_{\text {sat }}-R\right) \dot{\bar{\varepsilon}} \\
\dot{\beta}_{*}=m\left[\left(\frac{b}{B+R}\right)(\boldsymbol{\sigma}-\boldsymbol{\beta})-\boldsymbol{\beta}\right] \dot{\bar{\varepsilon}}
\end{gathered}
$$

Other advantage of the model, it can be used with the variable elasticity modulus. It is almost certain for the most researchers that the elasticity modulus of the materials variate with the given plastic deformations and it is given in Equation (11).

$$
E=E_{0}-\left(E_{0}-E_{A}\right)(1-\exp (-\xi \bar{\varepsilon}))
$$

As can be seen, the model can reflect the nonlinear behaviour of the elasticity modulus' variation with the given deformation. In the model, the E_0 is the initial elasticity modulus and E_A is the final elasticity modulus value for the given last unloaded deformation level. $\xi$ is the essential parameter that reflect the decreasing rate of the elasticity modulus with the given deformation. The decrease in the elasticity modulus of the materials is generally determined via the loading and unloading tests applied to tensile test specimens, and the model parameters can be determined via the loading and unloading stress strain data. However, it is also possible to determine indirectly this variation with the optimization process. Therefore, the $\mathrm{Y}-\mathrm{U}$ model can be defined by 9 parameters $(Y, c, B, R s a t, b, k, E a, \mathrm{ksi}, \mathrm{C} 1$ and $\mathrm{C} 2)$ that reflect the material behaviour.

\section{Materials and experiments}

Due to their high strength and low density, 5754-H22, 5083-O and 5005-O aluminium alloys, which are frequently used in aviation and automotive sectors, have been identified as target materials. The thickness of the selected materials is $0.97 \mathrm{~mm}$ for $5754-\mathrm{H} 22,2 \mathrm{~mm}$ for $5083 \mathrm{O}$ and $5005 \mathrm{O}$. The general mechanical properties of these materials were obtained at $25 \mathrm{~mm} / \mathrm{min}\left(0.0083 \mathrm{~s}^{-1}\right)$ deformation rate for test samples prepared in different rolling directions according to
ASTM E8 standard. The technical drawing of the sample according to ASTM E8 standard is given in Figure 3.

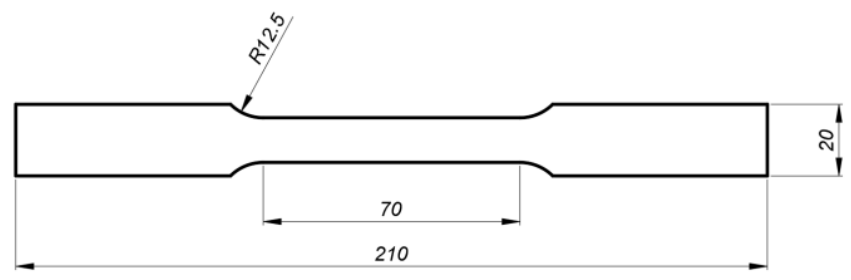

Figure 3. Tensile test specimen for ASTM-E8 standard

In order to prevent buckling during the test, cyclic compression-tensile tests were carried out in SHIMADZUAutograph $100 \mathrm{kN}$ tensile test machine with special apparatus where the test specimen shown in Figure 4 is compressed between the plates. Strain were measured by a video extensometer which synchronized with the tensile test machine. Since the video-extensometer follows two gauge marks drawn on the sample by means of two cameras, the plates are made of transparent plexiglass material. The technical drawing of the cyclic tensile test sample given in Figure 5 was adapted to our system with reference to the work of Tamura at al. [32]. For cyclic tensile-compression tests, the tensile test machine can be programmed for different limit values.

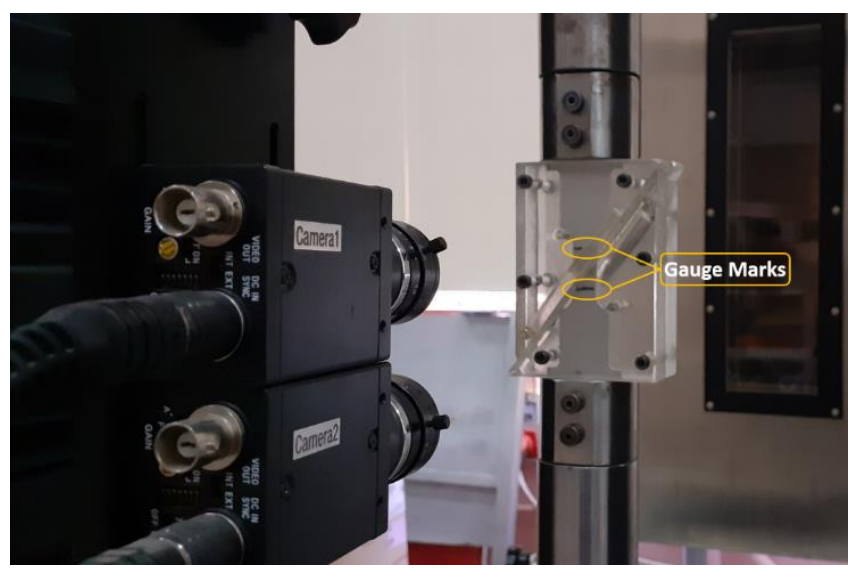

Figure 4. The cyclic experimental setup

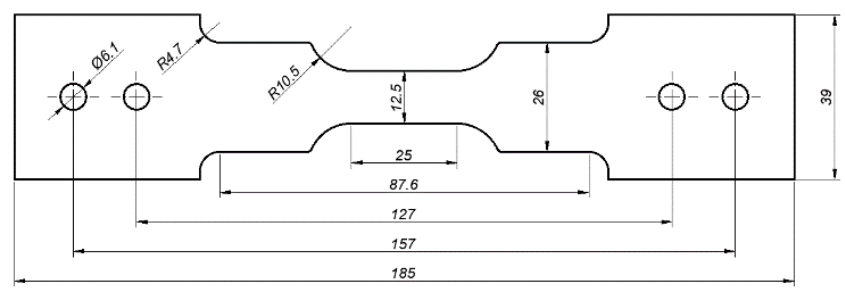

Figure 5. Technical drawing of the cyclic test sample

In this study, as shown in Figure 6 cyclic tensilecompression tests were carried out in three stages. The test specimens were tensile from stressless ( 0 strain value) to 0.01 strain value, then -0.01 strain value was compressed and then until the stress value on the material was 0 the load on the sample was unloaded. Cyclic tests were performed at a 
strain rate of $5 \mathrm{~mm} / \mathrm{min}\left(1.666 \times 10^{-3} 1 / \mathrm{s}\right)$. Although the stress values are not exactly compatible with the tensile curves, they have yielded close results.

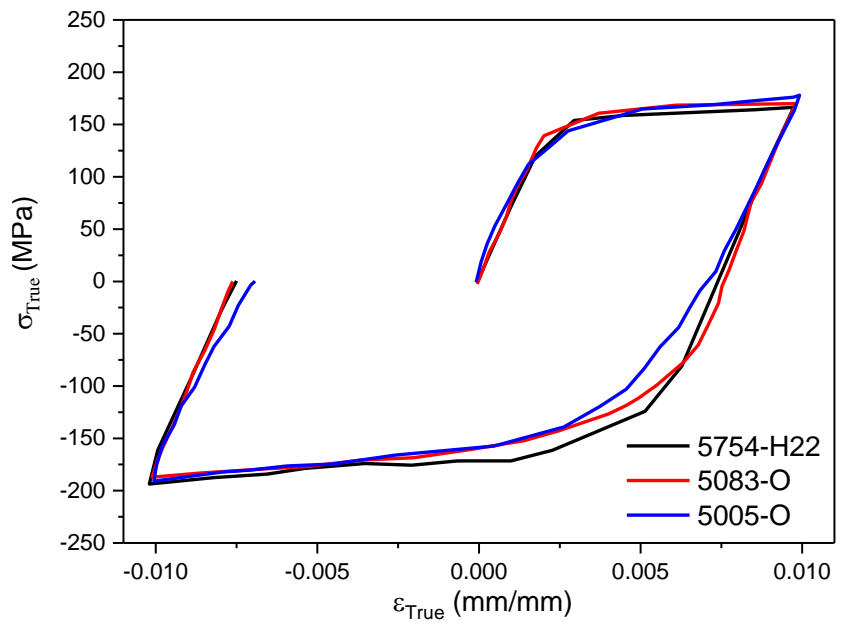

Figure 6. Cyclic tensile-compression test results of aluminium alloys

\section{Results and discussions}

The general mechanical properties required for forming analysis of the related materials were determined by tensile tests and the true stress unit deformation curves obtained are given in Figure 7 . When the stress values obtained from the samples in different rolling directions of the materials were evaluated, no significant difference was obtained, but the differences in total unit deformation values were obtained. Lankford parameters of the materials were determined by tensile tests and their general mechanical properties are given in Table 2.

Material parameters, Yoshida Uemori equations were converted into code in Matlab program and Genetic Algorithm in Matlab / Optimization tool and Bee Algorithm in Pham's study [20, 21] were tried to be determined by adapting to basic code. In order to determine the importance of data frequency when determined material parameters, each data sets were interpolated dense in the elastic region and sparse in the plastic region (Case 1), sparse in the elastic region and dense in the plastic region (Case 2), dense in the elastic region and dense in the plastic region (Case 3 ) and sparse in the elastic region and sparse in the plastic region (Case 4) (Figure 8).
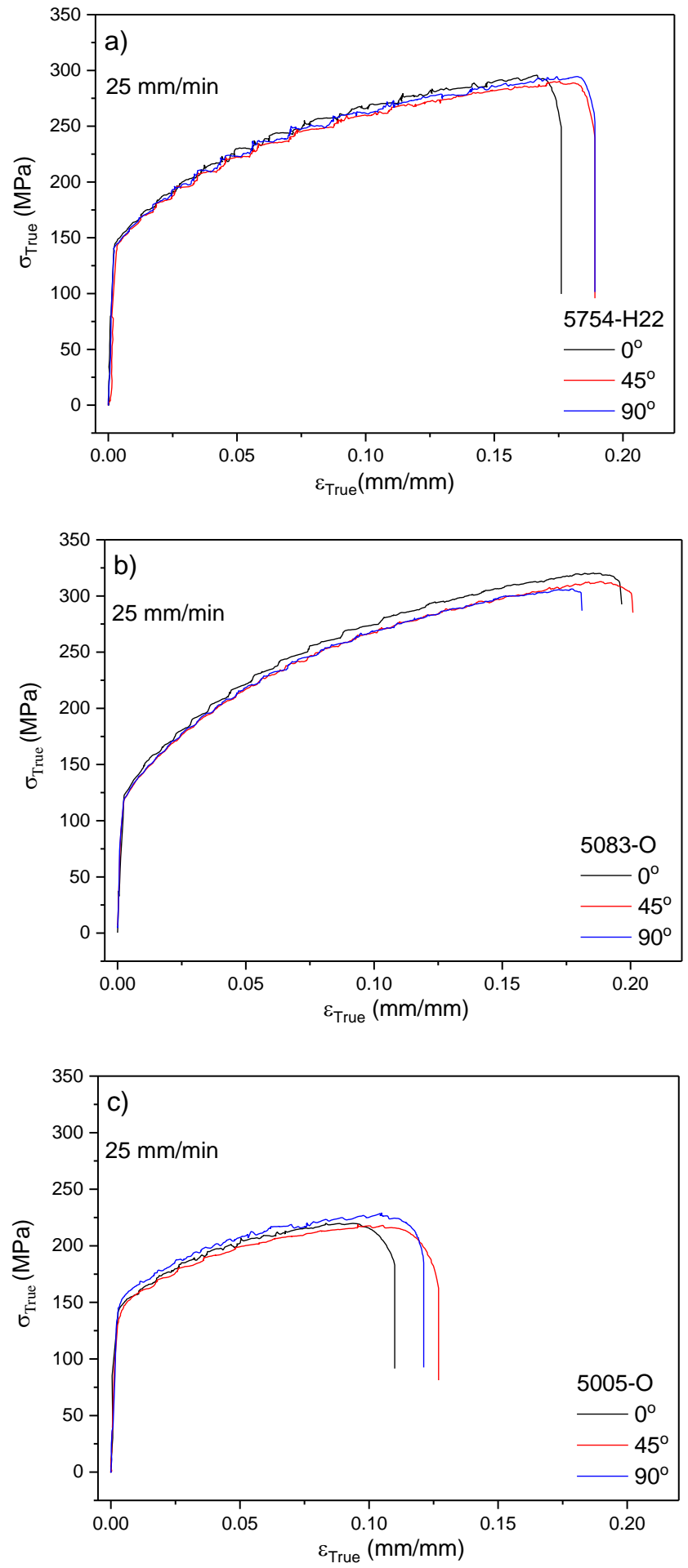

Figure 7. Tensile test results in different rolling directions; (a) $5754-\mathrm{H} 22$, (b) $5083-\mathrm{O}$, (c) $5005-\mathrm{O}$

Table 2. Mechanical properties of materials

\begin{tabular}{lccccccccc}
\hline Materials & $\sigma_{0}$ & $\sigma_{45}$ & $\sigma_{90}$ & $\varepsilon_{0}$ & $K$ & $n$ & $\mathrm{r}_{0}$ & $\mathrm{r}_{45}$ & $\mathrm{r}_{90}$ \\
\hline $5754-\mathrm{H} 22$ & 141.25 & 143.24 & 141.77 & 0.0022 & 425 & 0.20 & 0.50 & 0.66 & 0.61 \\
$5083-\mathrm{O}$ & 142.85 & 139.24 & 142.84 & 0.0036 & 594 & 0.29 & 0.53 & 0.79 & 0.50 \\
$5005-\mathrm{O}$ & 141.01 & 132.73 & 144.84 & 0.0028 & 310 & 0.14 & 0.46 & 0.76 & 0.69 \\
\hline
\end{tabular}



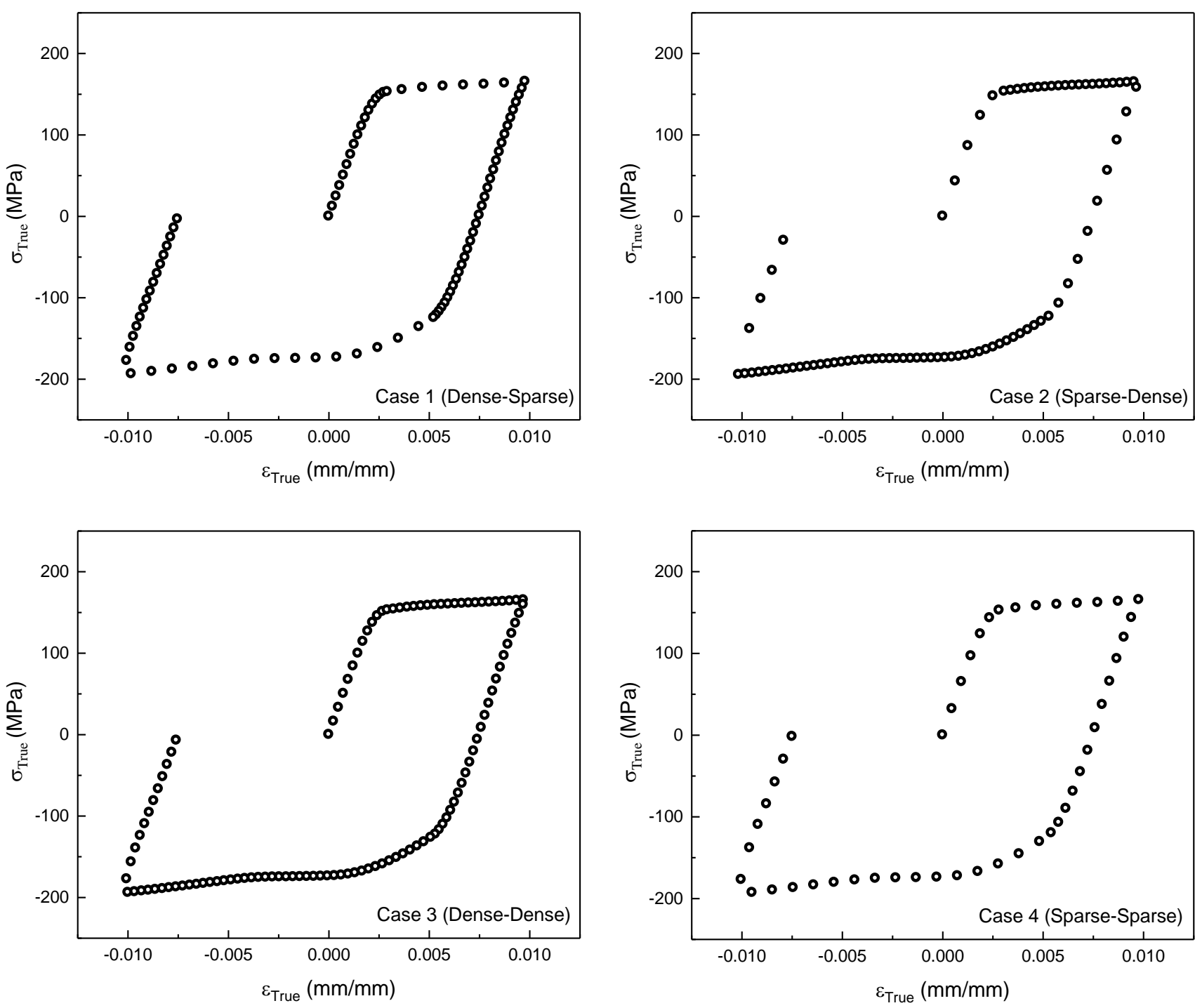

Figure 8. Different data frequency sets for Al 5754-H22 Material

Material parameters determined using The Bees Algorithm and Genetic Algorithm are given in Table 3 and Table 4. True stress-strain data calculated by curve fitting technique were compared with experimental data $\left(\mathrm{R}^{2}\right)$ as \% error. The error rates for all sets are given in Figure 9. In the analysis, it was observed that Genetic Algorithm and The Bees Algorithm give close values to each other. When Figure 9 is examined; Case 1 gave the best results for the $5083 \mathrm{BA}$ and 5083-GA sets and the worst for the 5754-GA set. Case 2 gave the best results for the 5005-BA and 5005-GA sets, while the 5754-BA gave the worst results for the 5083-BA and 5083-GA sets. Case 4 gave the best results for the $5754 \mathrm{BA}$ and $5754 \mathrm{GA}$ sets, while the worst results for the 5005-BA and 5005-GA sets. However, Case 3 did not give the worst results in any material set. The graph of the comparison of the experimental data with the material parameters obtained by using Case 3 for 50005-O material is shown in Figure 10.

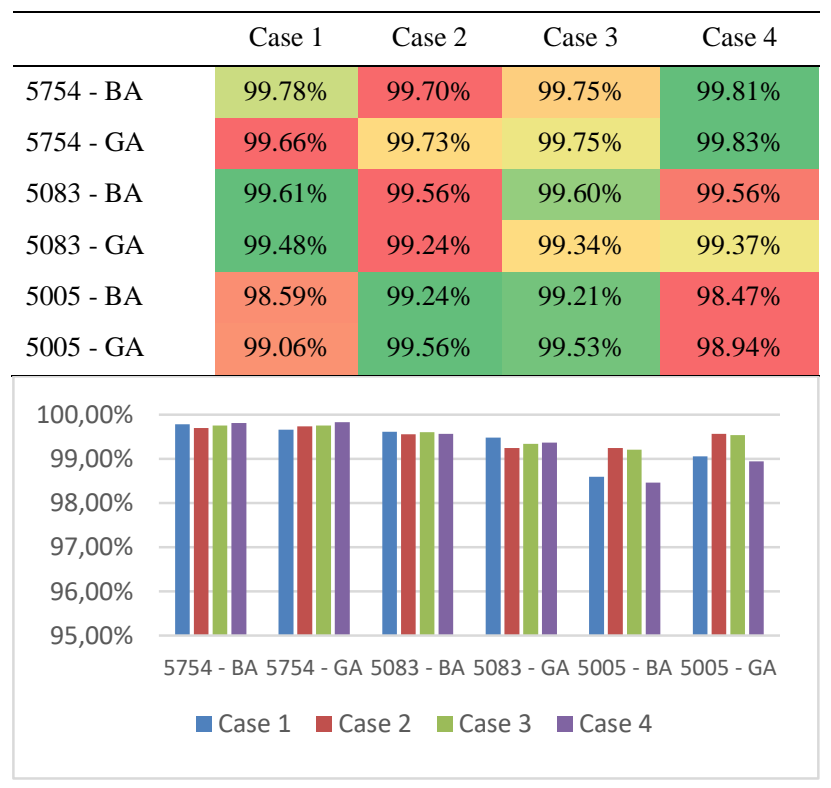

Figure 9. Error rates $\left(\mathrm{R}^{2}\right)$ of obtained material parameters 
Table 3. Yoshida Uemori model parameters determined by The Bees Algorithm

\begin{tabular}{|c|c|c|c|c|c|c|c|c|c|c|}
\hline Materials & $\mathrm{Y}$ & $\mathrm{c}$ & B & Rsat & $\mathrm{b}$ & $\mathrm{k}$ & $\mathrm{Ea}$ & ksi & $\mathrm{C} 1$ & $\mathrm{C} 2$ \\
\hline $\begin{array}{c}5754-\mathrm{H} 22 \\
\text { BA-Case } 1\end{array}$ & 134.895 & 483.537 & 171.741 & 187.104 & 69.279 & 15.392 & 67351 & -15.995 & 67.062 & 0.389 \\
\hline $\begin{array}{c}5754-\mathrm{H} 22 \\
\text { BA-Case } 2\end{array}$ & 144.820 & 114.787 & 226.169 & 381.130 & 96.265 & -13.022 & 68585 & -6.789 & 85.723 & 0.788 \\
\hline $\begin{array}{l}5754-\mathrm{H} 22 \\
\text { BA-Case } 3\end{array}$ & 141.459 & 187.602 & 200.326 & 399.203 & 37.105 & -12.449 & 71553 & 181.740 & 53.394 & 0.509 \\
\hline $\begin{array}{c}\text { 5754-H22 } \\
\text { BA-Case } 4\end{array}$ & 145.499 & 166.575 & 200.662 & 277.755 & 39.315 & -13.950 & 66961 & -12.036 & 91.256 & 0.731 \\
\hline $\begin{array}{c}5083-\mathrm{O} \\
\text { BA-Case } 1\end{array}$ & 140.670 & 208.501 & 170.958 & 280.214 & 52.422 & 30.158 & 68121 & -26.685 & 36.124 & 1.093 \\
\hline $\begin{array}{c}5083-\mathrm{O} \\
\text { BA-Case } 2\end{array}$ & 138.726 & 322.635 & 157.707 & 208.277 & 44.145 & 81.050 & 70704 & 152.989 & 20.325 & 0.390 \\
\hline $\begin{array}{c}5083-\mathrm{O} \\
\text { BA-Case } 3\end{array}$ & 142.084 & 123.938 & 195.264 & 225.999 & 31.756 & 18.697 & 70969 & 136.893 & 77.718 & 0.707 \\
\hline $\begin{array}{c}5083-\mathrm{O} \\
\text { BA-Case } 4\end{array}$ & 127.850 & 975.712 & 149.821 & 147.001 & 57.319 & 63.324 & 66676 & -16.491 & 89.172 & 0.769 \\
\hline $\begin{array}{c}5005-\mathrm{O} \\
\text { BA-Case } 1\end{array}$ & 110.450 & 216.091 & 129.399 & 448.590 & 85.206 & 123.415 & 64298 & 106.388 & 34.269 & 1.336 \\
\hline $\begin{array}{c}5005-\mathrm{O} \\
\text { BA-Case } 2\end{array}$ & 134.116 & 576.970 & 140.042 & 193.781 & 56.008 & 136.596 & 61151 & 189.097 & 89.506 & 0.183 \\
\hline $\begin{array}{c}5005-\mathrm{O} \\
\text { BA-Case } 3\end{array}$ & 131.244 & 168.485 & 134.305 & 453.347 & 68.916 & 129.956 & 62857 & 140.216 & 12.698 & 0.773 \\
\hline $\begin{array}{c}5005-\mathrm{O} \\
\text { BA-Case } 4\end{array}$ & 122.364 & 489.675 & 123.230 & 328.247 & 80.832 & 147.724 & 69045 & 54.920 & 93.943 & 0.656 \\
\hline
\end{tabular}

Table 4. Yoshida Uemori model parameters determined by Genetic Algorithm

\begin{tabular}{|c|c|c|c|c|c|c|c|c|c|c|}
\hline Materials & Y & $\mathrm{c}$ & B & Rsat & $\mathrm{b}$ & $\mathrm{k}$ & $\mathrm{Ea}$ & ksi & $\mathrm{C} 1$ & $\mathrm{C} 2$ \\
\hline $\begin{array}{c}5754-\mathrm{H} 22 \\
\text { GA-Case } 1\end{array}$ & 132.839 & 256.803 & 190.732 & 300.469 & 1.047 & 1.000 & 68961 & 31.115 & 99.995 & 0.015 \\
\hline $\begin{array}{c}5754-\mathrm{H} 22 \\
\text { GA-Case } 2\end{array}$ & 137.530 & 445.067 & 187.548 & 184.030 & 1.003 & 59.997 & 68438 & 2.631 & 99.999 & 0.014 \\
\hline $\begin{array}{c}5754-\mathrm{H} 22 \\
\text { GA-Case } 3\end{array}$ & 138.147 & 364.698 & 188.831 & 150.817 & 1.119 & 1.008 & 69871 & 184.743 & 99.948 & 0.049 \\
\hline $\begin{array}{c}5754-\mathrm{H} 22 \\
\text { GA-Case } 4\end{array}$ & 147.500 & 282.863 & 189.194 & 150.000 & 1.087 & 1.000 & 69937 & 5.875 & 45.670 & 0.077 \\
\hline $\begin{array}{c}5083-\mathrm{O} \\
\text { GA-Case } 1\end{array}$ & 132.074 & 283.821 & 185.032 & 308.427 & 1.069 & 1.134 & 68871 & 26.433 & 72.063 & 0.116 \\
\hline $\begin{array}{c}5083-\mathrm{O} \\
\text { GA-Case } 2\end{array}$ & 142.979 & 271.277 & 190.310 & 399.892 & 1.009 & 59.992 & 69842 & 199.994 & 42.095 & 0.9873 \\
\hline $\begin{array}{c}5083-\mathrm{O} \\
\text { GA-Case } 3\end{array}$ & 139.234 & 316.680 & 184.975 & 205.941 & 1.006 & 1.002 & 69540 & 199.996 & 99.997 & 0.0131 \\
\hline $\begin{array}{c}5083-\mathrm{O} \\
\text { GA-Case } 4\end{array}$ & 131.880 & 276.054 & 189.789 & 198.987 & 1.008 & 1.031 & 68737 & 25.455 & 67.653 & 0.0208 \\
\hline $\begin{array}{c}5005-\mathrm{O} \\
\text { GA-Case } 1\end{array}$ & 112.678 & 491.589 & 119.119 & 533.388 & 88.860 & 149.998 & 62174 & 20.473 & 81.479 & 0.896 \\
\hline $\begin{array}{c}5005-\mathrm{O} \\
\text { GA-Case } 2\end{array}$ & 145.395 & 234.440 & 166.823 & 599.996 & 32.366 & 149.999 & 62306 & 199.997 & 1.009 & 1.000 \\
\hline $\begin{array}{c}5005-\mathrm{O} \\
\text { GA-Case } 3\end{array}$ & 139.430 & 284.575 & 163.937 & 599.993 & 35.663 & 149.999 & 63285 & 110.336 & 1.008 & 1.000 \\
\hline $\begin{array}{c}5005-\mathrm{O} \\
\text { GA-Case } 4\end{array}$ & 126.834 & 647.204 & 134.031 & 428.454 & 74.792 & 149.990 & 62889 & 7.090 & 99.993 & 0.016 \\
\hline
\end{tabular}




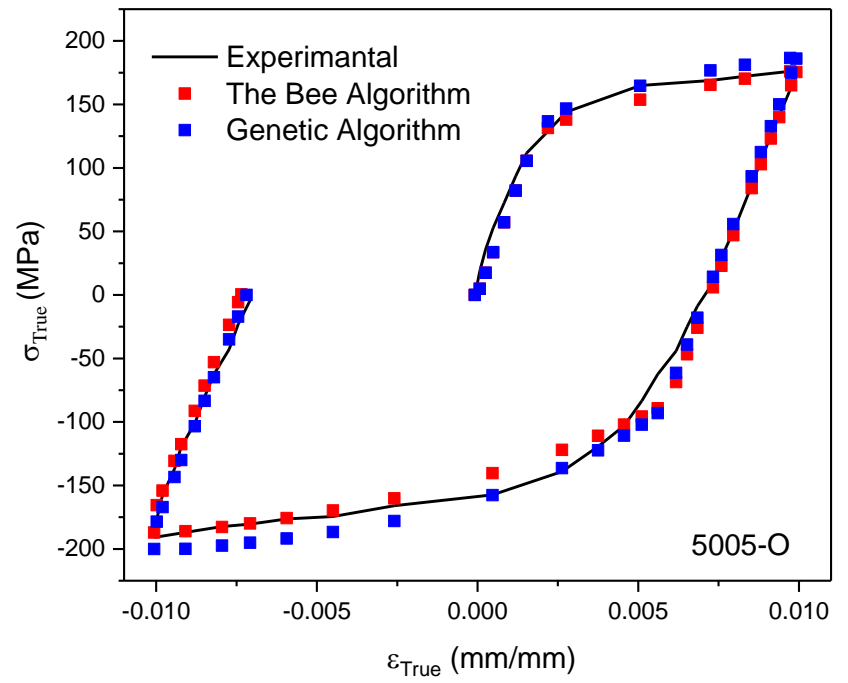

Figure 10. The results of the analysis using material parameters obtained with The Bees and Genetic Algorithms for $\mathrm{Al}$ 5005-O material

\section{Conclusion}

After Yoshida Uemori equations were coded in Matlab. The Bees and Genetic Algorithms were used to determine the material parameters of $5 \mathrm{xxx}$ series aluminium. When the results obtained from the analysis using the material model parameter obtained by The Bees Algorithm and the model parameter obtained by Genetic Algorithm were compared with the experimental data, it was observed that the two algorithms gave very close results. However, since The Bees Algorithm scans globally, it is possible to find the right roots even if the initial bound are not very good, but the initial bound for the Genetic Algorithm are of high importance.

In order to determine the importance of data density when determining material parameters, data sets were interpolated for 4 different cases. When the results of the material parameters obtained are examined, it is seen that the most stable result is given by Case 3 (Dense-Dense) data set and the most unstable result is given by State 2 (SparseDense) and Case 4 (Sparse Sparse) data sets.

\section{Conflict of interest}

The authors declare that there is no conflict of interest.

\section{Similarity Rate (iThenticate): \% 16}

\section{References}

[1] Y. K. Chen, X. X. Li, and L. H. Lang, Various elastic moduli of AA6016 and their application on accurate prediction of springback. Journal of the Chinese Institute of Engineers, 42, 319-326, May 192019. https://doi.org/10.1080/02533839.2019.1584765

[2] B. Chongthairungruang, V. Uthaisangsuk, S. Suranuntchai, and S. Jirathearanat, Springback prediction in sheet metal forming of high strength steels. Materials \& Design, 50, 253-266, Sep 2013. https://doi.org/10.1016/j.matdes.2013.02.060
[3] X. Xue, J. Liao, G. Vincze, A. B. Pereira, and F. Barlat, Experimental assessment of nonlinear elastic behaviour of dual-phase steels and application to springback prediction. International Journal of Mechanical Sciences, 117, 1-15, Oct 2016. https://doi.org/10.1016/ j.ijmecsci.2016.08.003

[4] S. Chatti and N. Hermi, The effect of non-linear recovery on springback prediction. Computers \& Structures, 89, 1367-1377, Jul 2011. https://doi.org/ 10.1016/j.compstruc.2011.03.010

[5] W. Prager, A new method of analyzing stresses and strains in work hardening plastic solids. ASME J. App. Mech 23, 493-496, 1956.

[6] T. Uemori, T. Okada, and F. Yoshida, Simulation of springback in $\mathrm{V}$-bending process by elasto-plastic finite element method with consideration of Bauschinger effect. Metals and Materials-Korea, 4, 311-314, 1998. https://doi.org/10.1007/BF03187783

[7] T. Uemori, T. Okada, and F. Yoshida, FE analysis of springback in hat-bending with consideration of initial anisotropy and the Bauschinger effect. Advances in Engineering Plasticity, Pts 1-2, 177-1, 497-502, 2000. https://doi.org/10.4028/www.scientific.net/KEM.177180.497

[8] F. Yoshida and T. Uemori, A model of large-strain cyclic plasticity describing the Bauschinger effect and workhardening stagnation. International Journal of Plasticity, 18, 661-686, 2002. https://doi.org/ 10.1016/S0749-6419(01)00050-X

[9] R. K. Boger, R. H. Wagoner, F. Barlat, M. G. Lee, and K. Chung, Continuous, large strain, tension/compression testing of sheet material. International Journal of Plasticity, 21, 2319-2343, 2005. https://doi.org/10.1016/j.ijplas.2004.12.002

[10] J. H. Kim, D. Kim, Y. S. Lee, M. G. Lee, K. Chung, H. Y. Kim, et al., A temperature-dependent elasto-plastic constitutive model for magnesium alloy AZ31 sheets. International Journal of Plasticity, 50, 66-93, Nov 2013. https://doi.org/10.1016/j.ijplas.2013.04.001

[11] M. G. Lee, D. Kim, C. M. Kim, M. L. Wenner, R. H. Wagoner, and K. Chung, Spring-back evaluation of automotive sheets based on isotropic-kinematic hardening laws and non-quadratic anisotropic yield functions - Part II: characterization of material properties. International Journal of Plasticity, 21, 883914, 2005. https://doi.org/10.1016/j.ijplas.2004.05.015

[12] F. Yoshida, T. Uemori, and K. Fujiwara, Elastic-plastic behavior of steel sheets under in-plane cyclic tensioncompression at large strain. International Journal of Plasticity, 18, 633-659, 2002. https://doi.org/10.1016/ S0749-6419(01)00049-3

[13] C. Y. Chang, M. H. Ho, and P. C. Shen, YoshidaUemori material models in cyclic tension-compression tests and shear tests. Proceedings of the Institution of Mechanical Engineers Part B-Journal of Engineering Manufacture, 228, 245-254, Feb 2014. https://doi.org/10.1177/0954405413499011 
[14] P. A. Eggertsen and K. Mattiasson, An efficient inverse approach for material hardening parameter identification from a three-point bending test. Engineering with Computers, 26, 159-170, Apr 2010. https://doi.org/10.1007/s00366-009-0149-y.

[15] P. A. Eggertsen and K. Mattiasson, On the identification of kinematic hardening material parameters for accurate springback predictions. International Journal of Material Forming, 4, 103-120, Jun 2011. https://doi.org/10.1007/s12289-010-1014-7

[16] S. Toros, Parameters determination of Yoshida Uemori model through optimization process of cyclic tensioncompression test and V-bending springback. Latin American Journal of Solids and Structures, 13, 1893 1911, 2016. https://doi.org/10.1590/1679-78252916

[17] A. H. Mahmoudi, S. M. Pezeshki-Najafabadi, and H. Badnava, Parameter determination of Chaboche kinematic hardening model using a multi objective Genetic Algorithm. Computational Materials Science, 50, 1114-1122, Jan 2011. https://doi.org/10.1016/ j.commatsci.2010.11.010

[18] J. H. Yongfeng Li, Bin Gu, Shuhui Li, Identification of advanced constitutive model parameters through global optimization approach for DP780 steel sheet. Procedia Engineering, 207, 125-130, 2017. https://doi.org/ 10.1016/j.proeng.2017.10.749

[19] D. T. Pham and M. Castellani, Benchmarking and comparison of nature-inspired population-based continuous optimisation algorithms. Soft Computing, 18, 871-903, May 2014. https://doi.org/10.1007/ s00500-013-1104-9

[20] D. T. Pham, A. Ghanbarzadeh, E. Koç, S. Otri, S. Rahim, and M. Zaidi, The Bees Algorithm technical note. Manufacturing Engineering Centre, 1-57, 2005.

[21] D. T. Pham, A. Ghanbarzadeh, E. Koç, S. Otri, S. Rahim, and M. Zaidi, The Bees Algorithm - A novel tool for complex optimisation problems. Manufacturing Engineering Centre, 454-458, 2006. https://doi.org/10.1016/B978-008045157-2/50081-X

[22] A. A. Fahmy, M. Kalyoncu, and M. Castellani, Automatic design of control systems for robot manipulators using the bees algorithm. Proceedings of the Institution of Mechanical Engineers Part I-Journal of Systems and Control Engineering, 226, 497-508, Apr 2012.

[23] D. T. Pham, E. Koç, M. Kalyoncu, and M. Tınkır, Hierarchical PID controller design for a flexible link robot manipulator using The Bees Algorithm. Proceedings of Proceedings of 6th International Symposium on Intelligent Manufacturing Systems, Sakarya, Turkey, 2008.

[24] D. T. Pham and M. Kalyoncu, Optimisation of a Fuzzy Logic Controller for a flexible single-link robot arm using The Bees Algorithm. Proceedings of 7th IEEE International Conference on Industrial Informatics, Cardiff, UK, 2009.

[25] M. A. Sen, V. Bakırcığlu, and M. Kalyoncu, Performances comparison of The Bees Algorithm and Genetic Algorithm for PID controller tuning. Proceedings of 5th International Mechatronics and Control Engineering, Venice, Italy, 2016.

[26] O. Öztürk, M. Kalyoncu, and A. Ünüvar, Multi objective optimization of cutting parameters in a single pass turning operation using The Bees Algorithm. Proceedings of 1st International Conference on Advances in Mechanical and Mechatronics Engineering, Ankara/TURKEY, 2018.

[27] O. Acar, M. Kalyoncu, and A. Hassan, The design optimization of a gripper mechanism using The Bees' Algorithm. Proceedings of International Conference on Engineering Technologies (ICENTE'18), Konya/TURKEY, 2018.

[28] O. Acar, M. Kalyoncu, and A. Hassan, Proposal of a harmonic Bees Algorithm for design optimization of a gripper mechanism, Cham, 2019, 2829-2839. https://doi.org/10.1007/978-3-030-20131-9_280

[29] Anonymous. (2019). MATLAB global optimization toolbox sser's guide. Available: https://www. mathworks.com/help/gads/index.html. (Accessed March 12nd, 2021)

[30] P. C. B. Abdulaziz Alghtani, D.C. Barton, V.V. Toropov, Springback analysis and optimization in sheet metal forming. Proceedings of 9th European LSDYNA Conference, Manchester, 2013.

[31] D. E. G. Ali Aryanpour, Evaluation of LS-DYNA material models for the analysis of sidewall curl in advanced high strength steels. Proceedings of 12th International LS-DYNA Conference, Detroit, 2012.

[32] S. Tamura, S. Sumikawa, T. Uemori, H. Hamasaki, and F. Yoshida, Experimental observation of elastoplasticity behavior of type 5000 and 6000 aluminum alloy sheets, Materials Transactions, 52, 868-875, May 2011. https://doi.org/10.2320/matertrans.L-MZ201101 